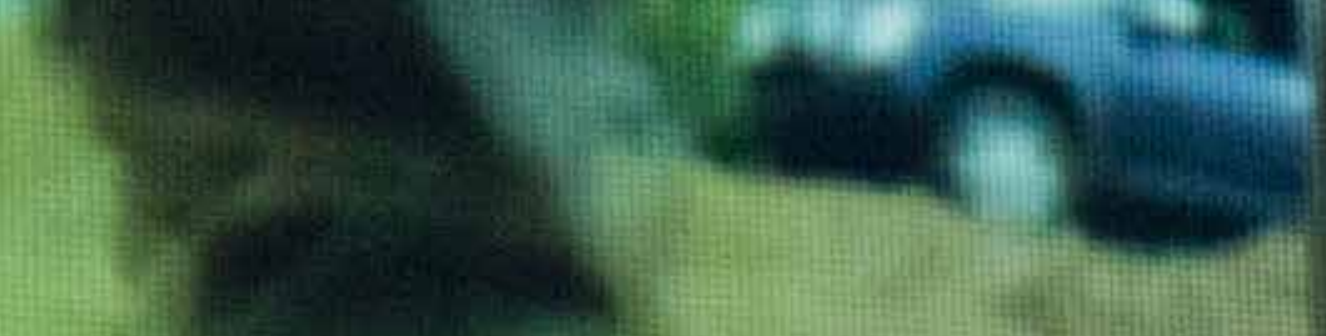

$-$
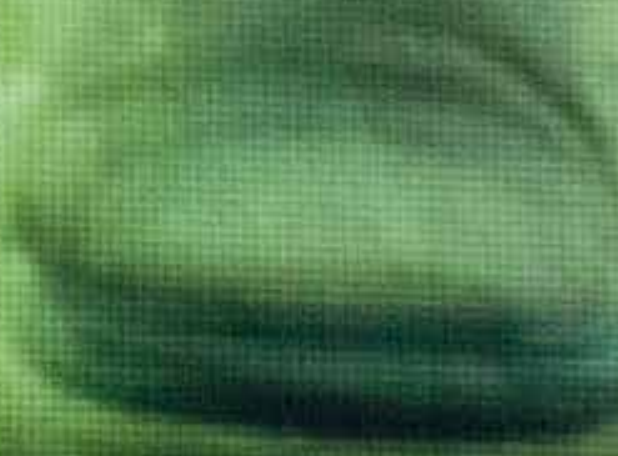

Hation:

4xitat

fititi:

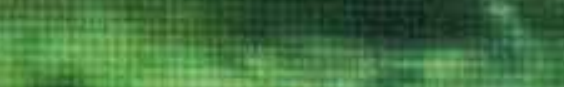

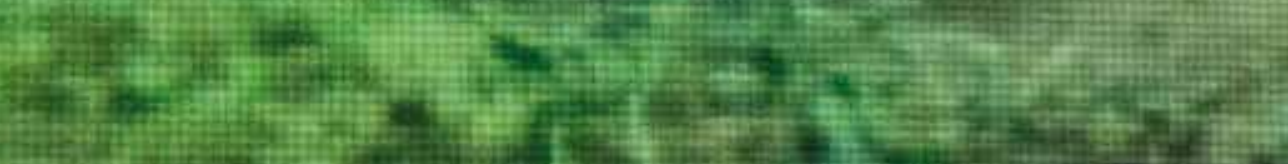

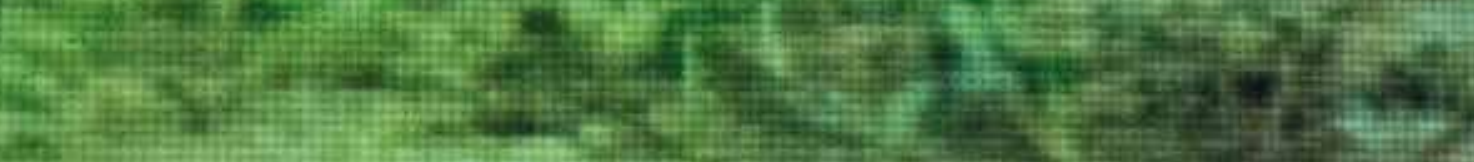

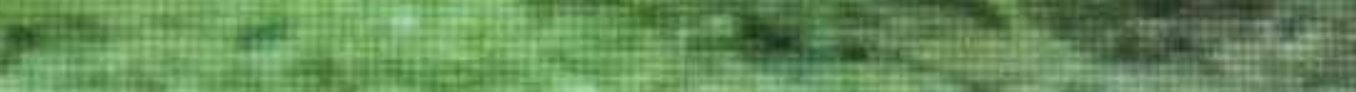

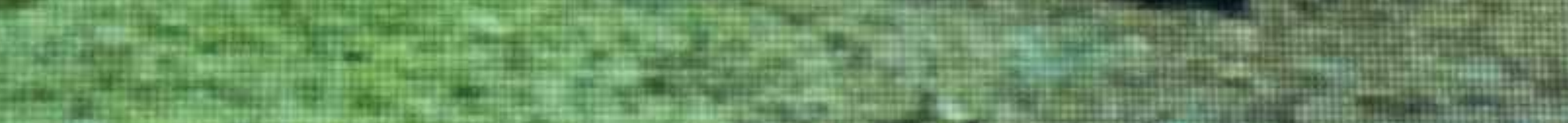

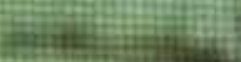

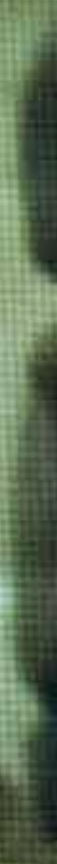

Pitititis

a

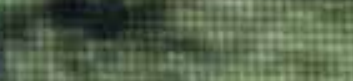

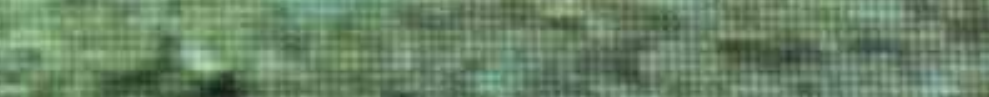
W

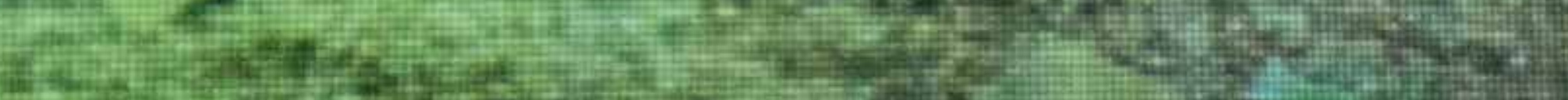

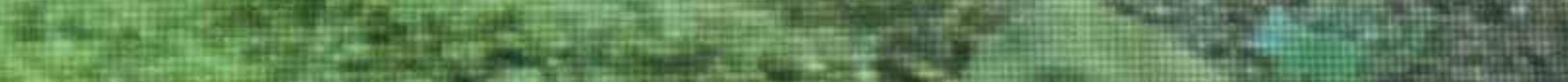

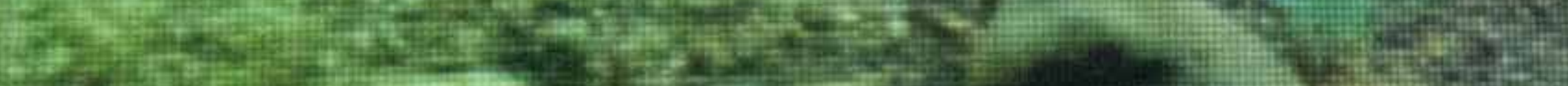

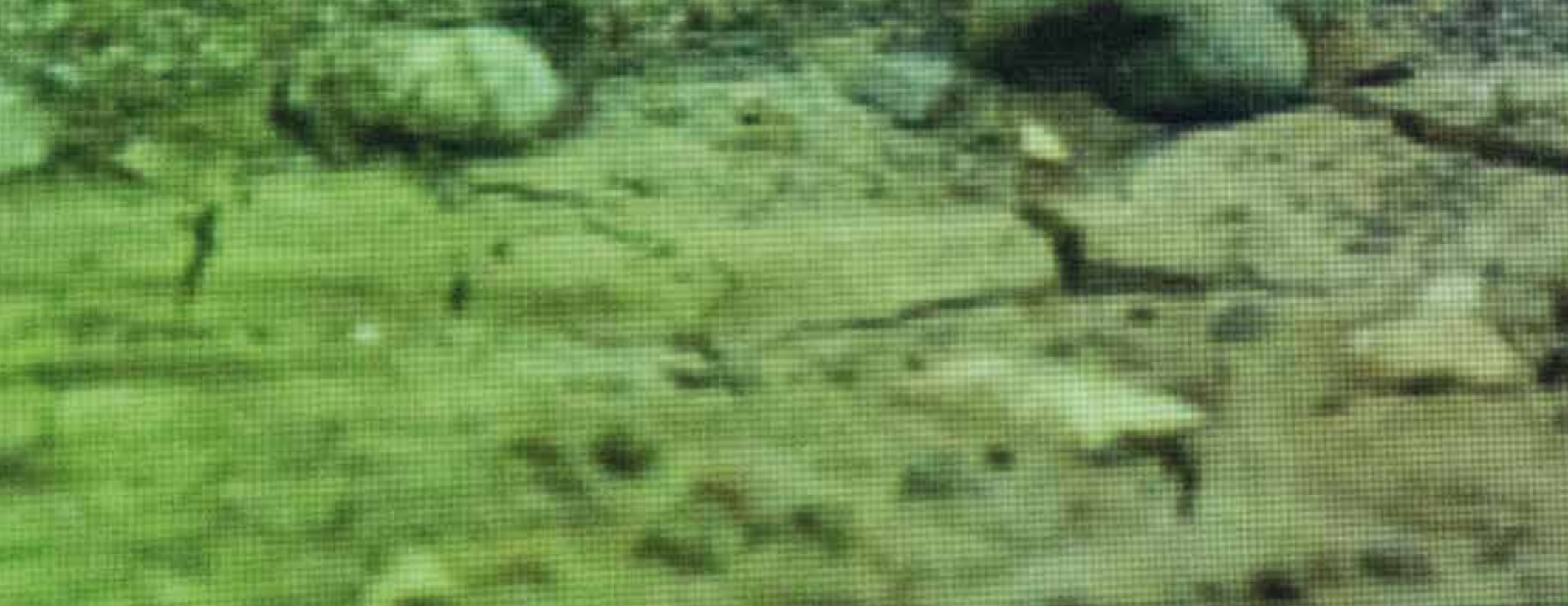




\section{Formación de la}

empatía a través del uso

de la imagen artística.

El caso de las víctimas

de la violencia en

\section{Colombia}

Sandra Marcela Ríos Rincón 


\title{
Resumen
}

El siguiente texto presenta algunos resultados obtenidos en el desarrollo de la investigación doctoral "Imagen artística, aprendizaje emocional y memoria en el contexto escolar. El caso de las víctimas del conflicto armado en Colombia" que en la actualidad se adelanta en la Universidad Autónoma de Barcelona. El estudio pretende determinar la incidencia de una propuesta de innovación educativa en la enseñanza del conflicto armado. Va dirigida a estudiantes entre Io a I3 años de edad que corresponde a sexto grado de educación primaria en colegios oficiales de Bogotá.

\section{Palabras clave:}

Imagen artística, enseñanza de la historia reciente, empatía, conflicto armado, emotividad.

Formation of Empathy Through the Use of Artistic Image. The Case of Victims of Violence in Colombia

\begin{abstract}
The following text presents some results obtained in the development of the doctoral research entitled "Artistic Image, emotional learning and memory in the school context. The case of the victims of the armed conflict in Colombia," which is currently being carried out at the Autonomous University of Barcelona. The study seeks to determine the incidence of a proposal of educational innovation in the teaching of armed conflict. It is aimed at students between IO and 13 years of age, corresponding to $6^{\text {th }}$ grade of primary education in official schools in the city of Bogota.
\end{abstract}

Keywords: Artistic image; teaching recent history; empathy; armed conflict; emotivity.

Formação da empatia através do uso da imagem artística. $O$ caso das vítimas da violência na Colômbia

\section{Resumo}

O seguinte texto apresenta alguns resultados obtidos no desenvolvimento da pesquisa de doutorado "Imagem artística, aprendizagem emocional e memória no contexto escolar. O caso das vítimas do conflito armado na Colômbia", em curso atualmente na Universidade Autônoma de Barcelona. O estudo visa determinar a incidência de uma proposta de inovação educativa no ensino do conflito armado, dirigida a estudantes entre io e I3 anos, correspondentes ao sexto ano de educação primária em colégios públicos de Bogotá.

Palavras chave: imagem artística; ensino da história recente; empatia; conflito armado; emotividade. 


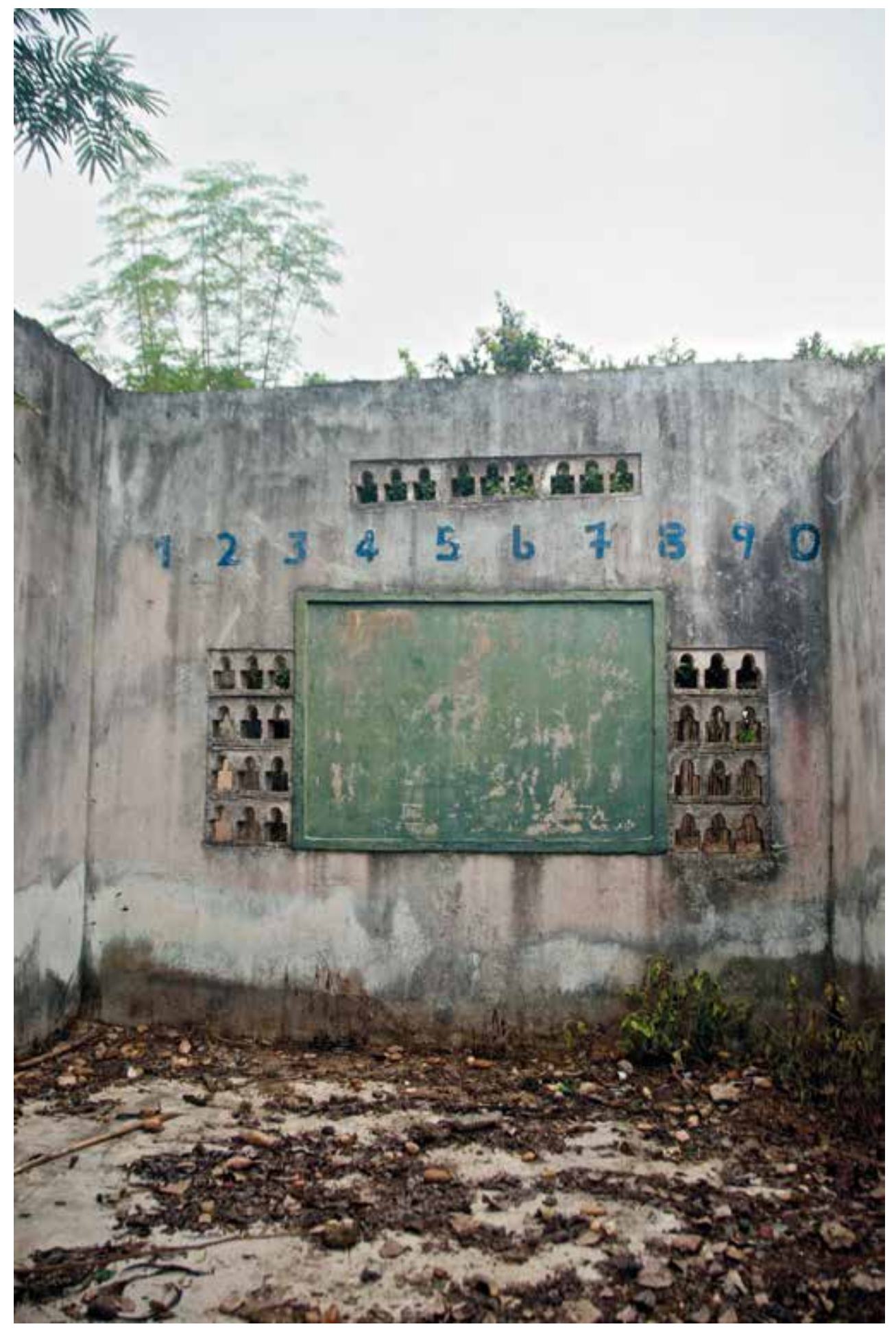

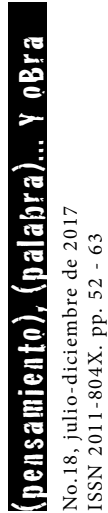




\section{Introducción}

El documento presenta el análisis de un estudio de caso que pretende evaluar la capacidad de empatía que presentan los estudiantes frente a las víctimas del conflicto armado colombiano. La investigación pretende ayudar a los estudiantes a colocarse en el lugar del otro, ubicándose en múltiples perspectivas frente a una situación que les permita crear nuevas formas de entendimiento e interrelación social. El estudio recoge las percepciones y emociones relacionadas con el uso de la imagen artística (pintura) en este mismo grupo de estudiantes.

El trabajo parte del hecho de considerar importante no solo los conocimientos históricos sino la parte emotiva que surge de ello y la interlocución con la memoria en este tipo de hechos.

Se reconoce una ausencia en la enseñanza de la historia reciente en nuestro país, la cual afecta de manera directa su comprensión por parte de los estudiantes. Esta ausencia se explica fundamentalmente por dos razones, la primera es la falta de propuestas didácticas innovadoras que motiven a los estudiantes a conocer el conflicto armado, la segunda es la resistencia a su enseñanza por parte de los docentes la cual se explica porque es un tema que aún hoy sigue siendo bastante polémico ya que actúa sobre las fibras más sensibles de la sociedad colombiana.

\section{Emotividad y enseñanza de la historia}

Un punto de partida importante para este estudio es el hecho de considerar que la emotividad juega un papel significativo en la comprensión de temáticas históricas recientes, en particular aquellas ligadas a hechos traumáticos o polémicos del acontecer nacional, en este caso el conflicto armado. Se inicia al entender el proceso enseñanza-aprendizaje de la historia escolar como un asunto complejo que implica no solo promover conocimiento y pensamiento científico, sino también comprender el campo emotivo y de los sentimientos.

Este campo ha sido muy poco estudiado y tratado desde la perspectiva didáctica, lo cual descuida las implicaciones que tiene en la formación de un pensamiento histórico y político, no solo en los años escolares sino en la vida adulta de los estudiantes.

El ámbito de las emociones no puede ser subestimado en el proceso de posicionamiento político de los individuos y en la formación de una opinión pública colectiva. Sin duda, constituye una parte importante de la explicación a la actuación y la justificación de los juicios de los individuos. Edgar Morin señala que frente a los nuevos retos de la sociedad contemporánea es necesario remitirse a nuevos vínculos que superen el pensamiento cognitivo-intelectual y que se acerquen al campo emocional y valórico. La relación entre razón y afectividad explica nuestras reacciones y actitudes y ninguna de las dos es superior a la otra (Morin, 1999), de allí que la enseñanza de los contenidos escolares pueda ser tan importante como la promoción de la emotividad y afectividad entre seres humanos.

Las emociones en el campo escolar se manifiestan cuando valoramos (positiva o negativamente) nuestro yo en relación con actuaciones individuales o grupales (Pagés, et. al., 20I4). Las podemos definir como un estado de alteración afectiva originado normalmente por una situación que puede ser amenazante, frustrante o sencillamente activadora para el sujeto (Alonso, et. al., 2006). Esta investigación intenta encontrar estas alteraciones emotivas frente a dispositivos artísticos que pueden ser utilizados como recurso de enseñanza en el aula, para este caso la pintura.

\section{La imagen artística como activador de la empatía}

La imagen en la enseñanza de la historia ha sido utilizada tradicionalmente por docentes de ciencias sociales. Habitualmente este recurso didáctico se usa con el fin de que los estudiantes asocien ciertas imágenes con un período o hecho histórico específico.

Las posibilidades de trabajar en el aula con recursos didácticos icónicos facilitan los procesos de aprendizaje de la historia y la comprensión de la realidad socio cultural correspondiente a la vida cotidiana de una época. La relación que se da entre el arte y la enseñanza de la historia puede fundamentarse en la idea que plantea Trepat (20II, p 90) al afirmar que "la obra de arte, por otra parte, en el marco de la enseñanza de la historia constituye una fuente primaria de indiscutible valor, que puede ser utilizada como motivación, e incluso como eje para efectuar una primera aproximación a un periodo histórico determinado".

Es tal la importancia del uso de la imagen en la enseñanza de la historia, que para algunos historiadores puede equipararse a un archivo documental o una fuente primaria, "los textos o los testimonios orales, las imágenes son una forma importante de documento histórico" (Burke, 200I, pI7).

No obstante el uso de la imagen como recurso didáctico puede ofrecer otras posibilidades para el desarrollo del pensamiento histórico. Santisteban (2010, p 39) propone cuatro tipologías para este fin; la construcción de la conciencia histórico- temporal, las formas de representación de 


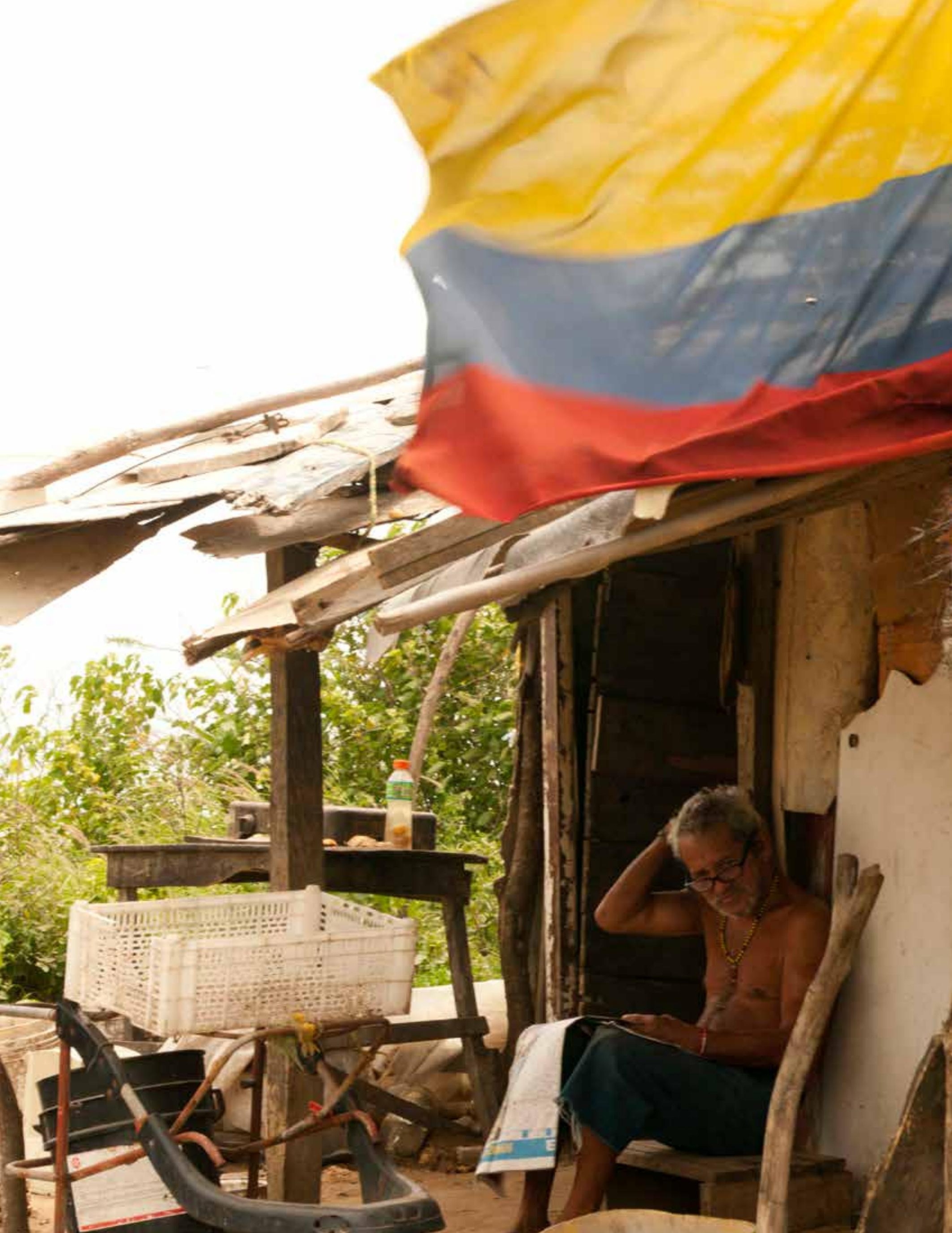


la historia, el aprendizaje de la interpretación histórica y la imaginación/creación histórica. Esta última, según el autor es la que genera la capacidad de la formación en la empatía la cual conlleva al análisis histórico y el desarrollo del pensamiento crítico.

Así la formación de la empatía con fines educativos, especialmente en la enseñanza de la historia, permite a los estudiantes la construcción de valores sociales y morales, preparándolos así para la vida democrática de estos. (Santisteban, 2010, p 47).

Esta competencia, al estar relacionada con la formación del pensamiento crítico, le otorga al alumnado instrumentos para entender la realidad social que lo rodea, ser capaz de comprender y respetar puntos de vista diferentes, percibir o sentir las afectaciones de otras personas con el fin de actuar en sociedad y lograr la construcción de un mundo más justo y solidario.

Estas capacidades sociales, morales y afectivas situadas en un escenario educativo, finalmente colaboran en la formación de la sensibilidad del alumno a favor de la reflexión en cuestiones socioculturales.

\section{La enseñanza de la historia reciente en Colombia}

Es importante reconocer que la enseñanza de la historia reciente en Colombia no ha estado caracterizada por propuestas didácticas innovadoras que permitan al estudiante interesarse por el conocimiento de estos hechos históricos y a la vez tener en cuenta elementos de carácter emotivo en su aprendizaje y discusión. Por tanto, la investigación apunta a promover la formación de competencias de pensamiento histórico, en particular la empatía fundamentada tanto en el conocimiento del pasado como en el reconocimiento de las emociones individuales de cada estudiante.

La violencia, tomada como hecho social y no tanto como elemento interpersonal, no es ausente de las realidades y contextos cotidianos de muchos de los jóvenes de nuestro país, antes al contrario es vivenciada de manera más o menos cercana por ellos en la medida en que el contexto de la sociedad colombiana está marcado por su carácter violento.

En Colombia el campo de la enseñanza de las ciencias sociales escolares y en particular el de la historia, ha sido bastante descuidado en la medida en que diferentes reformas educativas lo vinieron diluyendo en una integración con otras disciplinas lo que terminó convirtiéndolo en un campo difuso sin claridad en la propuesta de contenidos y métodos de enseñanza. Adicionalmente, se ha venido entendiendo la enseñanza de la historia escolar como una historia científica alejada tanto de los aspectos pedagógicos, sociales y educativos que por definición encierran su práctica; como más importante aún de la realidad de los estudiantes. Este tipo de entendimiento de la historia escolar, separado de los adelantos y discusiones en la disciplina histórica y su enseñanza, pervive en muchas instituciones educativas del país barnizado con algún discurso de carácter crítico-constructivista. Lo anterior lo confirma el Grupo de Investigación en la Enseñanza de la Historia (GIEH) de la Universidad Nacional de Colombia (2007) cuyos miembros hace algunos años constataban que:

En cuanto a la primaria y en particular la secundaria, a lo largo del siglo XX y en buena medida hasta la actualidad, la enseñanza de la historia y la geografía se ha mantenido con enfoque enciclopedista, con un dejo peyorativo pero "necesario" referido a la enseñanza de "cultura general". Aún se considera como persona culta aquella que posee unos conocimientos (contenidos/temas) que se le han trasmitido y ha memorizado. Podría decirse, que era y sigue siendo como el vestuario, un adorno complementario de la persona, que puede lucir en reuniones sociales.

Pero lo que es aún más grave es el analfabetismo histórico que esto ha conllevado con lo cual el conocimiento de la realidad actual se hace aún menos comprensible en las generaciones actuales. Esta situación se hace especialmente compleja cuando tenemos en cuenta que Colombia ha vivido una guerra civil no declarada entre movimientos armados de izquierdas y el Estado, la cual lleva más de cincuenta años y debido a su prolongación pierde su sentido ya que las nuevas generaciones no pueden responder claramente a las preguntas del porqué o cómo se da inicio a la guerra y que la lleva a su continuidad.

La guerra y el conflicto han marcado a las últimas generaciones sin distinguir clase social y procedencia geográfica o cultural en Colombia. La escuela como institución y sus actores, maestros y estudiantes no han sido la excepción, bien sea como víctimas directas del conflicto o como testigos de la violencia permanente que afecta a sus instituciones muchas de las cuales se encuentran en zonas directas del conflicto. Este panorama plantea una paradoja: una escuela rodeada por una guerra que a su vez se resiste a analizarla sin convertirla en una temática de estudio con estrategias pertinentes a su carácter volátil y polémico.

Pareciera que la escuela en Colombia estuviera eclipsada por una visión "eficientista" y "productivista" en la cual lo más importante es el cumplimiento de los estándares, competencias y lineamientos curriculares promovidos desde el Ministerio de Educación Nacional construidos sin la participación efectiva de los maestros y atendiendo, por el contrario, a estándares y parámetros internacionales de evaluación y medición. 
Esta paradoja permite explicar -en parte- por qué no se ha encontrado un espacio propicio para la incorporación de la enseñanza de la historia reciente o de la memoria y su relación con el conflicto armado ni como contenido curricular ni como tema emergente de trabajo pedagógico. Sin embargo, la principal razón de la ausencia en la escuela de temáticas relacionadas con la historia reciente, y en particular con el conflicto armado, se puede asociar al alto grado de polémica que aún suscita esta cuestión en la sociedad actual al ser transversal en la vida y experiencia vital de prácticamente todos los colombianos.

El panorama actual en Colombia muestra a los maestros reacios a incluir temas que pueden promover antagonismos o levantar heridas aún no cerradas. Aparece una ausencia de métodos didácticos que permitan hacer énfasis en la enseñanza desde el punto de vista histórico y de formación de una conciencia histórica cercana al dolor de las víctimas donde lo académico se conjugue con lo emotivo.

En Colombia la falta de memoria histórica o lo que se planteó anteriormente como analfabetismo histórico, no implica que no exista una cierta memoria colectiva por parte de los estudiantes de la violencia social y política y del conflicto armado en Colombia. Esta memoria es aquella a la que se refería Halbwachs (2004) cuando afirmaba que el recordar no ocurre de manera aislada sino que por el contrario acontece en el interior de un contexto social donde están presentes las instituciones y la cultura, por tanto aunque la memoria funciona al interior del sujeto, es finalmente el contexto social el que le da sentido creándola y recreándola según las situaciones culturales, económicas y políticas que caracterizan un momento histórico determinado.

Por esto, los estudiantes ya tienen una memoria colectiva del conflicto armado que ha sido moldeada a través de los marcos sociales en los que se desenvuelven, los medios de comunicación, la familia y en general la cultura.

En conclusión, la enseñanza de la historia reciente en Colombia se encuentra bastante limitada por la ausencia de docentes que asuman su enseñanza, como por ayudas didácticas que permitan que los estudiantes se motiven en aprenderlas. La enseñanza del conflicto armado en Colombia no es un contenido de primer orden para los docentes de ciencias sociales, debido a que es un tema que genera aún un alto grado de polémica. La falta de recursos didácticos se debe en parte a que los docentes se enfocan en el cumplimiento de estándares, competencias y lineamientos internacionales.

\section{Supuestos de investigación}

Como se mencionó el objetivo de este texto es presentar la capacidad de empatía que presentan los estudiantes frente a las víctimas del conflicto armado colombiano. Parte de esta premisa se basa en la idea que plantea P. Waldmann Augburg (1997) al afirmar que la violencia en Colombia se ha convertido en un fenómeno cotidiano. La "cotidianización" de la violencia permea todas las capas de la sociedad colombiana, Waldmann lo expresa con las siguientes palabras:

Se la practica en público o en privado, por individuos o por grupos, de manera espontánea o premeditada, para alcanzar fines políticos, económicos o personales, dentro de las capas bajas, pero también por personas pertenecientes a la clase media o a la alta, en las ciudades grandes y en las medianas, y alcanza hasta los rincones más recónditos de este, en parte, tan accidentado territorio.

Esta exposición frecuente a la violencia conlleva a que la sociedad colombiana presente cierto grado de insensibilidad en relación con los hechos de agresión que genera el conflicto armado. Damián Fernández (200I, p I6) lo explica desde la teoría del aprendizaje observacional, el cual se presenta al existir una estrecha relación entre medios de comunicación y violencia. El estudio de Fernández muestra que la susceptibilidad del receptor de un mensaje, si es sometida frecuentemente a estímulos agresivos, se ve afectada y forma en dicho receptor una reacción de insensibilidad, lo que conlleva a una aceptación gradual de la violencia como algo natural.

En un estudio previo, aún no publicado, realizado por la autora en el año 2016 en cinco colegios oficiales de la ciudad de Bogotá indagó a I59 estudiantes por las fuentes de conocimiento de las cuales provenían sus nociones sobre el conflicto armado. Los resultados demuestran que los medios de comunicación son quienes tienen mayor influencia. Ver gráfica I. 


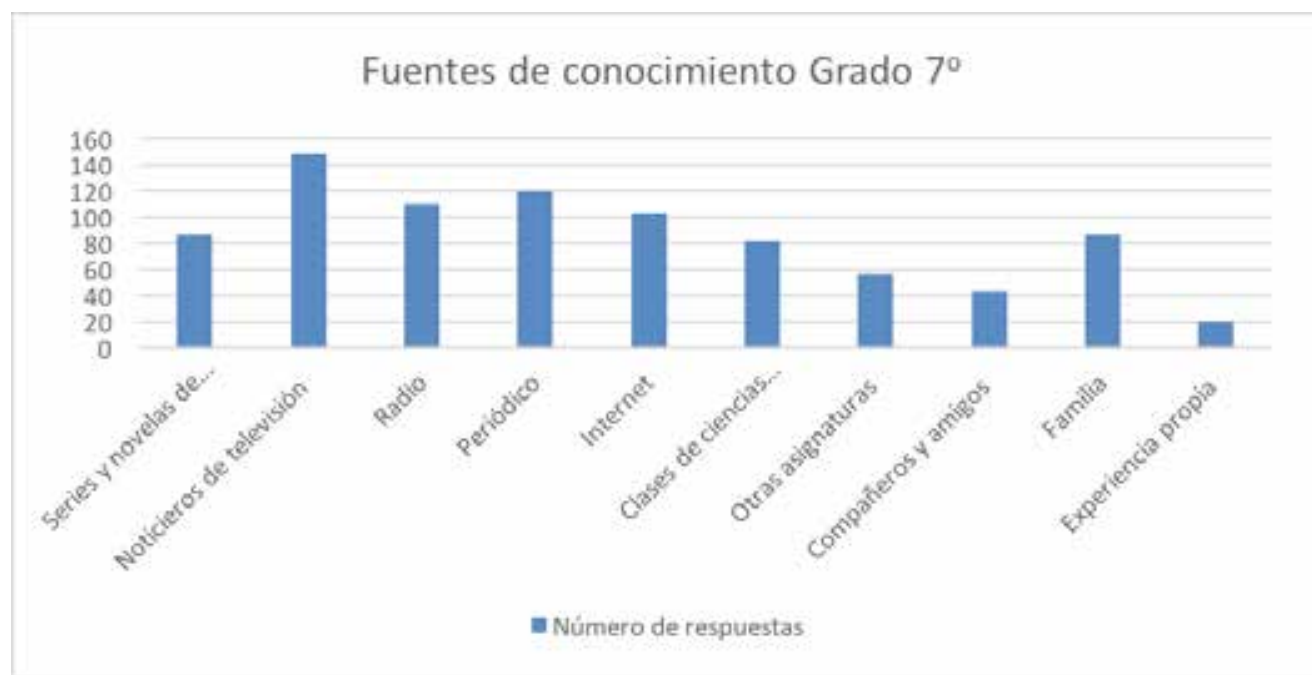

Gráfica I. Fuentes de conocimiento de estudiantes de grado $7^{\circ}$ en relación con el coflicto armado

Los medios de comunicación tienden a distorsionar la información en búsqueda de mayores audiencias y se enfocan al sensacionalismo mediático, ofreciendo al estudiante una información descontextualizada, de poco análisis, cargada de alto contenido violento o influenciada por alguna tendencia política o interés económico, generando en ellos una idea errónea, parcial o manipulada del conflicto armado.

En consecuencia de lo anterior, la sociedad colombiana terminará desolidarizándose, sobre todo con aquellos que han vivido la violencia en primera persona. Esta desensibilización emocional no es ajena al contexto escolar, si se acude a la idea de que las aulas son parte y reflejo de esta. Por lo tanto, tratar una temática como la del conflicto armado en la escuela es un escenario inmejorable para ayudar a comprender y sensibilizar a las nuevas generaciones de la inutilidad de la guerra y la violencia.

La necesidad de vincular la enseñanza de la historia con lo emotivo no ha estado presente de manera evidente en el campo de la enseñanza de las ciencias sociales en Colombia. En este sentido, se parte de entender que el proceso enseñanza-aprendizaje de la historia escolar es un asunto complejo que implica no solo promover conocimiento y pensamiento científico, sino que también promueva la reflexión desde el campo emotivo y de los sentimientos.

\section{Metodología del estudio}

El estudio se establece tomando como referencia la teoría fundamentada planteada por Strauss y Corbin (2002) que en términos generales afirma la importancia de recopilar datos de manera sistemática y analizarlos por un proceso de investigación. Desde esta perspectiva, la recolección de datos, el análisis y la teoría que surjan de ellos guardan estrecha relación entre sí. Por tanto, en el desarrollo de la investigación no se pretende partir de teorías y explicaciones ya establecidas sino que por el contrario, los resultados surgirán de un análisis de los datos recopilados en estrecha relación con la realidad educativa encontrada. Desde esta perspectiva, se plantea que las categorías, la codificación y los conceptos surjan del análisis de la información recopilada fundamentada en los datos cuantitativos recogidos a través de instrumentos validados.

\section{Contexto de investigación}

La población objeto de estudio se centra en estudiantes del Colegio Distrital María Mercedes Carranza ubicado en la localidad de Ciudad Bolívar. La propuesta se llevó a cabo con alumnos de $6^{\circ}$ grado de edades comprendidas entre los II y I3 años, en la asignatura de Ciencias Sociales, jornada mañana, en total 35 estudiantes participaron de la experiencia.

La investigación se fundamenta en la aplicación de un cuestionario en el que se indaga por las percepciones emotivas de los estudiantes alrededor de la temática del conflicto armado sugeridas por imágenes artísticas pictóricas.

El cuestionario examinó la manera como los estudiantes reaccionan emotivamente frente a pinturas de diferentes artistas colombianos que hacen alusión a las víctimas en el conflicto armado. 
Para establecer las reacciones emotivas se recurrió a la clasificación de Robert Plutchik (1980) que categoriza las emociones en ocho campos:

Interés /anticipación/vigilancia/optimismo.

Enfado/ira/furia/agresividad.

Tedio /aversión/odio/desprecio.

Melancolía/tristeza/pena/remordimiento.

Distracción/sorpresa/asombro/decepción.

Temor/miedo/terror/susto.

Aprobación /confianza/admiración/sumisión.

Serenidad /alegría/éxtasis/amor.

La intensidad emocional varía, según Plutchik de un individuo a otro. Las emociones varían según la intensidad dentro de cada categoría y este hecho amplía mucho el rango de emociones que se experimentaron.

El cuestionario fue puesto en conocimiento de los docentes de Ciencias Sociales que participaron en el estudio quienes aportaron comentarios y ajustes que ayudaron a su validación.

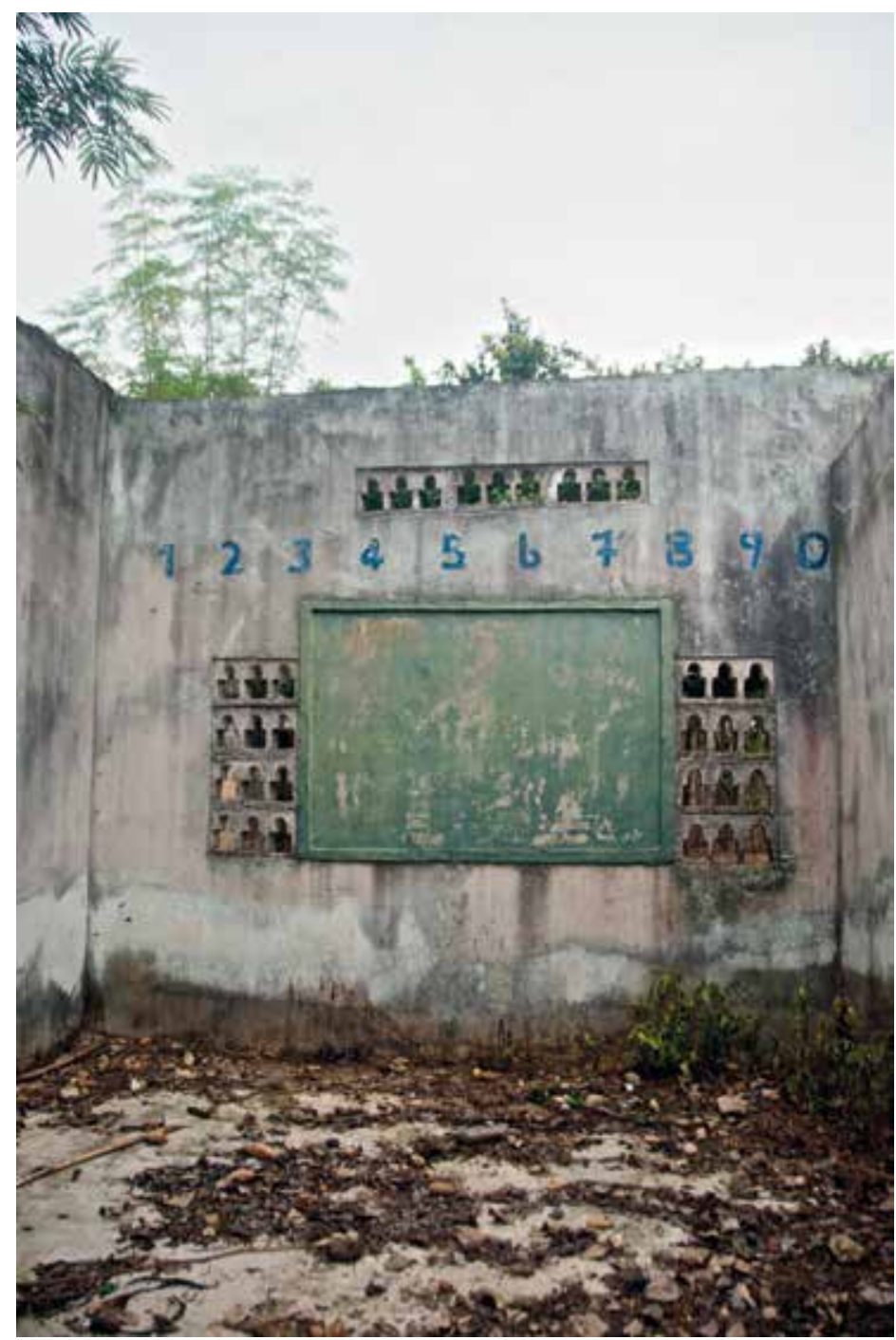

Miradas que generan emotividad en el entorno del conflicto armado

La investigación pretende descifrar la manera en que los estudiantes de este nivel reaccionan emotivamente frente a algunas imágenes artísticas concernientes con la temática.

Se parte del hecho -como se mencionó inicialmente - de considerar que las emociones juegan un papel importante en la configuración tanto del conocimiento escolar como de las opiniones y formas de comprender que se le otorgan a hechos históricos polémicos que poseen una carga sensible importante.

Con este propósito la investigación acude a imágenes artísticas que puedan suscitar reacciones emotivas, lo cual se devela, la manera como impacta a los estudiantes este tipo de recurso y la forma más apropiada de utilizarlo como estrategia de enseñanza desde lo emocional.

Las imágenes utilizadas fueron cuatro pinturas; dos del autor Alipio Jaramillo, una de Sair García y la última del reconocido pintor Fernando Botero

\section{Algunos resultados}

Los resultados señalan que la categoría que más recurrentemente fue nombrada como evocadora de emociones fue la de melancolía/tristeza/pena/remordimiento. Esto se explica si se observan las imágenes en las que la tragedia de la guerra es una constante. 
Ahora bien, la segunda categoría que se observa es relevante, tiene que ver con el sentimiento de temor/miedo/terror/susto. Es posible que esta situación tenga que ver con la edad de los estudiantes (II-I3 años) que pueden ser más susceptibles a este tipo de imágenes.

Esta categoría del temor va acompañada de una mayor disposición al enfado/ira/furial agresividad. Lo que se deduce es que cuanto más explícita es la imagen en la demostración de violencia aumenta consecuentemente el nivel de enfado y agresividad de los estudiantes. Parece una especie de reacción primaria como medio de defensa en una situación violenta.

\section{Gráfica 16: Consolidado total de emociones en pinturas}

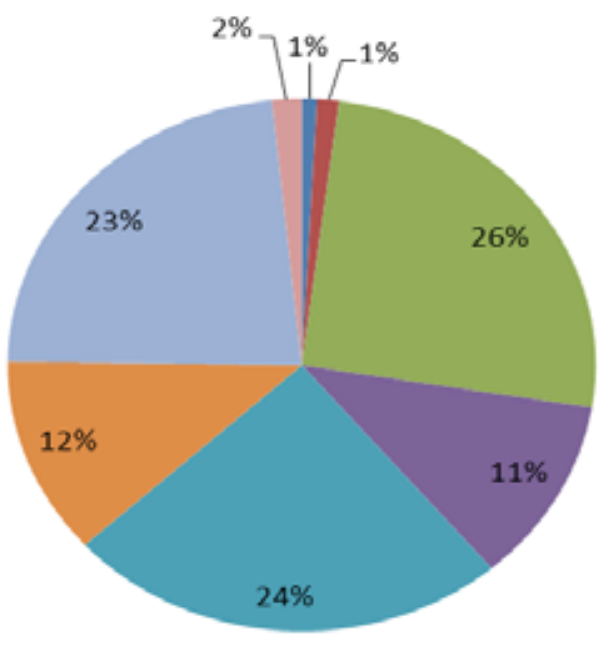

Eerenidad, Alegria, Exasis, Amor

E Aprobación, Confianza, Admiración, Simisión

= Temor, miedo, Terror, Susto

Distracción, Sorpresa, Asombro, Decepción,

= Melancolia, Tristeza, Pena, Remordimiento

= Tedio, Aversión, Odio, desprecio

Enfado, Ira, Furia, Agresividad

= Interés, Anticipación, Vigilancia, Optimismo

Gráfica 2. Categorias de las emociones

\section{Conclusiones}

El conflicto armado tiene una exposición mediática muy amplia que llega a los estudiantes por múltiples canales, en particular se exponen aquellos hechos violentos que se desprenden de él, lo cual conduce a que la Escuela no alcance a asimilar esta sobreexposición lo cual dificulta ligarla a contenidos curriculares concretos.

Este tema debería ser tratado como una temática escolar y analizada desde el punto de vista académico lo que ayudaría a preferenciar razones de tipo histórico y político que expliquen la realidad actual de la guerra en Colombia no desde la opinión irreflexiva sino desde el conocimiento profundo de la realidad social.

En cuanto al uso de las imágenes artísticas y la reacción emotiva que generan, se puede concluir que las imágenes asociadas con la guerra, el conflicto y la violencia tienden a generar sentimientos de tristeza, pena y melancolía en los estudiantes. Este resultado evidencia que la imagen artística se constituye como un recurso valioso para promover la empatía con las víctimas del conflicto armado.

El tema por su naturaleza tiende a ocasionar este tipo de emociones por lo cual es importante para una propuesta didáctica equilibrar esta tendencia con el uso de historias resilientes que tengan como elemento contundente la esperanza, el perdón y la reconciliación. 
Alonso, Plá F. M., Esteban Martínez, C., Calatayud Miñana, C., Alamar Rocatí, B., y Egido Portela, Á. (2006). Emociones y conducción: Teoría y fundamentos. Madrid: Attitudes.

Burke, P. (2005). Visto y no visto: el uso de la imagen como documento histórico. Barcelona: Crítica.

Fernández, Pedemonte D. (200I). La violencia del relato. Discurso periodístico y casos policiales. Buenos Aires: La Crujía Ediciones.

Grupo de Investigación en la Enseñanza de la Historia (GIEH), Universidad Nacional de Colombia (2007). Orientaciones curriculares para el campo de pensamiento histórico. Bogotá: Secretaría de Educación. Alcaldía Mayor de Bogotá D.C.

Halbwachs, M. (2004). Los marcos sociales de la memoria. Barcelona: Editorial Anthropos.

Morin, E. (1999). Los siete saberes necesarios para la educación del futuro. París: Unesco.

Pagés, J., Martínez-Valcárcel, N, M., y Aldunate, M., M, C. (20I4). El tiempo histórico: construcción y referentes en la memoria del alumnado. En Pagés, J., Martínez-Valcárcel, N., Cachari-Aldunate, M., (Coords.) La historia de España en los recuerdos escolares: análisis e interpretación y poder de cambio de los testimonios de profesores y alumnos (pp. 229-265). Valencia: Nau Libres.

Plutchik, R. (1980). Emotion: theory, research, and experience. New York: Academica Press.

Trepal, C. A., Prieto-Puga, R., Santacana, J., Souto, X., y Prats, J. (20II). Didáctica de la Geografía y la Historia. Barcelona: Graó.

Santisteban, A. (20I0). La formación de competencias de pensamiento histórico. Clío \& Asociados, I4, 34-56.

Strauss, A., y Corbin, J. (2002). Bases de la investigación cualitativa. Técnicas y procedimientos para desarrollar la teoría fundamentada. Medellín: Editorial Universidad de Antioquia.

Waldmann Augburg. P. (1997). Cotidianización de la violencia: El ejemplo de Colombia. Revista Análisis Político, 32, 33-52.

Sandra Marcela Ríos Rincón. Licenciada en Ciencias Sociales de la Universidad Pedagógica Nacional. Magíster en Investigación Social Interdisciplinaria de la Universidad Distrital Francisco José de Caldas. Docente de Ciencias Sociales de la Secretaría de Educación de Bogotá. Miembro del Grupo de Investigación Pedagogía y Ciencias Sociales. Estudiante del Doctorado en Educación de la Universidad Autónoma de Barcelona.

riosdelrincon@hotmail.com

Artículo recibido en enero del 2017 y aceptado en marzo del 2017

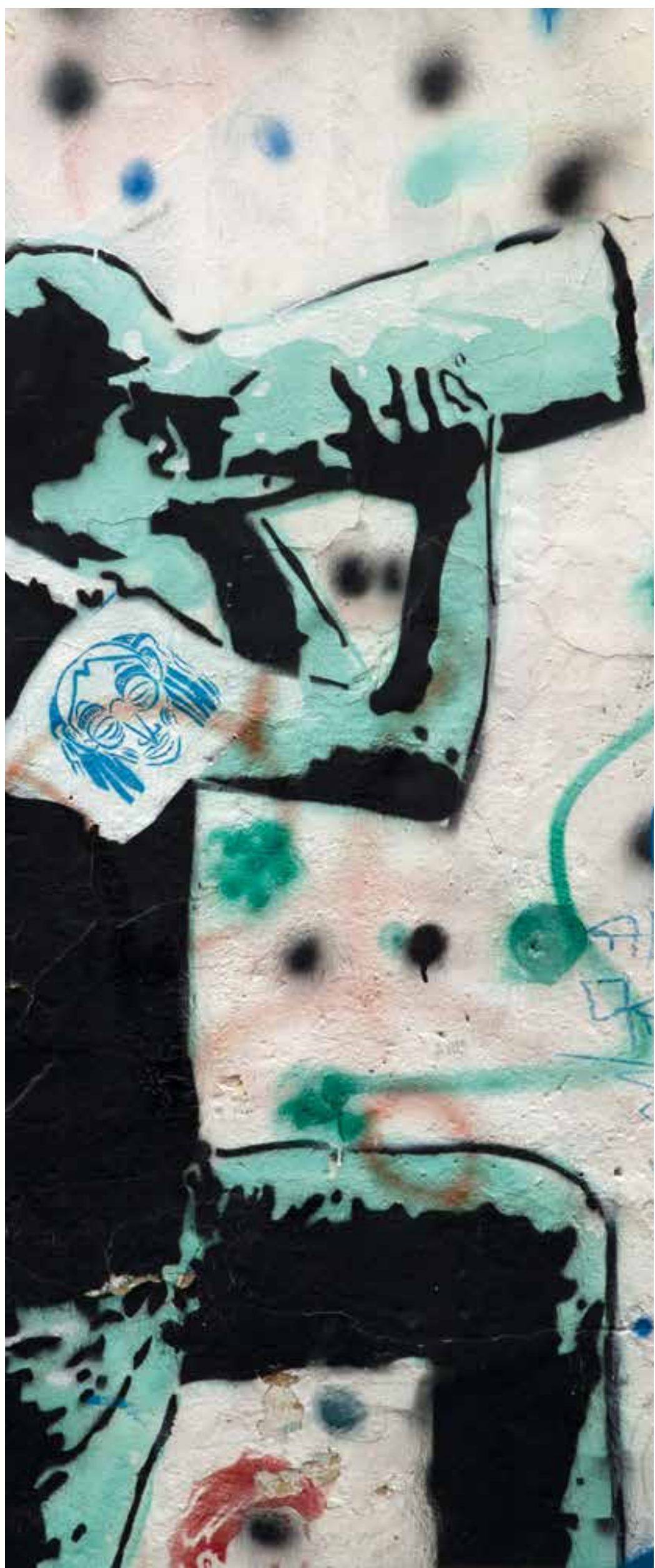

